\author{
Marquette University \\ e-Publications@Marquette
}

Biomedical Engineering Faculty Research and

Publications

Biomedical Engineering, Department of

$11-2016$

\title{
Effect of Surgical Fusion on Volitional Weight-Shifting in Individuals With Adolescent Idiopathic Scoliosis
}

\author{
Nikhil T. Kurapati \\ Medical College of Wisconsin \\ Joseph Krzak \\ Shriners Hospitals for Children \\ Adam Graf \\ Shriners Hospitals for Children \\ Sahar Hassani \\ Shriners Hospitals for Children \\ Sergey Tarima \\ Medical College of Wisconsin
}

See next page for additional authors

Follow this and additional works at: https://epublications.marquette.edu/bioengin_fac

Part of the Biomedical Engineering and Bioengineering Commons

\section{Recommended Citation}

Kurapati, Nikhil T.; Krzak, Joseph; Graf, Adam; Hassani, Sahar; Tarima, Sergey; Sturm, Peter F.; Hammerberg, Kim W.; Gupta, Purnendu; and Harris, Gerald F., "Effect of Surgical Fusion on Volitional Weight-Shifting in Individuals With Adolescent Idiopathic Scoliosis" (2016). Biomedical Engineering Faculty Research and Publications. 462.

https://epublications.marquette.edu/bioengin_fac/462 


\section{Authors}

Nikhil T. Kurapati, Joseph Krzak, Adam Graf, Sahar Hassani, Sergey Tarima, Peter F. Sturm, Kim W. Hammerberg, Purnendu Gupta, and Gerald F. Harris 


\title{
Effect of Surgical Fusion on Volitional Weight-Shifting in Individuals with Adolescent Idiopathic Scoliosis
}

\author{
Nikhil T. Kurapati \\ Department of Orthopaedic Surgery, \\ Medical College of Wisconsin, \\ Milwaukee, WI \\ College of Engineering, Marquette University, \\ Milwaukee, WI \\ Motion Analysis Laboratory, Shriners Hospital for Children, \\ Chicago, IL \\ Joseph J. Krzak \\ Motion Analysis Laboratory, Shriners Hospital for Children, \\ Chicago, IL \\ Physical Therapy Program, College of Health Sciences, \\ Midwestern University, \\ Downers Grove, IL \\ Adam Graf \\ Motion Analysis Laboratory, Shriners Hospital for Children, \\ Chicago, IL
}


NOT THE PUBLISHED VERSION; this is the author's final, peer-reviewed manuscript. The published version may be accessed by following the link in the citation at the bottom of the page.

\author{
Sahar Hassani \\ Motion Analysis Laboratory, Shriners Hospital for Children, \\ Chicago, IL \\ Sergey Tarima \\ Division of Biostatistics, Medical College of Wisconsin, \\ Milwaukee, WI \\ Peter F. Sturm \\ Motion Analysis Laboratory, Shriners Hospital for Children, \\ Chicago, IL \\ Division of Orthopaedic Surgery, \\ Cincinnati Children's Hospital Medical Center, \\ Cincinnati, $\mathrm{OH}$ \\ Kim Hammerberg \\ Motion Analysis Laboratory, Shriners Hospital for Children, \\ Chicago, IL \\ Purnendu Gupta \\ Motion Analysis Laboratory, Shriners Hospital for Children, \\ Chicago, IL \\ Gerald F. Harris \\ College of Engineering, Marquette University, \\ Milwaukee, WI \\ Motion Analysis Laboratory, Shriners Hospital for Children, \\ Chicago, IL
}

\begin{abstract}
Study Design: Prospective.

Objectives: The goals of this study were to (1) evaluate the differences in weightbearing symmetry between individuals with adolescent idiopathic scoliosis (AIS) and typically developing controls; (2) observe the effect of posterior spinal fusion and instrumentation (PSFI) on volitional weight-shifting at 1 and 2 years postoperatively; and (3) evaluate whether lowest instrumented fusion level (ie, lowest instrumented vertebra [LIV]) in PSFI has an effect on volitional weight-shifting.
\end{abstract}

Spine Deformity, Vol 4, No. 6 (November 2016): pg. 432-438. DOI. This article is (C) Elsevier and permission has been granted for this version to appear in e-Publications@Marquette. Elsevier does not grant permission for this article to be further copied/distributed or hosted elsewhere without the express permission from Elsevier. 
NOT THE PUBLISHED VERSION; this is the author's final, peer-reviewed manuscript. The published version may be accessed by following the link in the citation at the bottom of the page.

Summary of Background Data: Previous studies have conflicting findings with regard to the effect of scoliosis on postural control tasks as well as the effect of surgery. They have also noted an inconsistent effect of PSFI at different LIVs, with more distal LIVs exhibiting greater reductions in postoperative range of motion.

Methods: The study was designed with an AIS group of 41 patients ( 8 males and 33 females) with AIS who underwent PSFI, along with a Control Group of 24 age-matched typically developing participants (12 male and 12 female). Both groups performed postural control tasks (static balance and volitional weight-shifting), with the AIS group repeating the tasks at 1 and 2 years postoperatively.

Results: At baseline, the AIS group showed increased weightbearing asymmetry than the Control Group $(p=.01)$. The AIS group showed improvements in volitional weight-shifting at 2 years over baseline $(p<.01)$. There was no effect of LIV on volitional weight-shifting by the second postoperative year.

Conclusions: Individuals with AIS have greater weightbearing asymmetry but improved volitional weight-shifting over typically developing controls. PSFI improves volitional weight-shifting beyond preoperative baseline but does not differ significantly by LIV.

Keywords: Scoliosis, Postural control, Posterior instrumentation and fusion

\section{Introduction}

There is a lack of consensus on the effect of scoliosis on postural control in those with adolescent idiopathic scoliosis (AIS), and this may be due to recent overemphasis on studying standing balance over volitional movement. Some investigators have noted that those with AIS exhibit increased sway $\underline{1}, \underline{2}, \underline{3}, 4, \underline{5}, \underline{6}, \underline{7}, \underline{8}, \underline{9}$ whereas others have found no difference at all $\underline{10}, \underline{11}$ or a difference with a visual challenge. $\underline{2}, \underline{12}, \underline{13}, \underline{14}$ Others have reported participants with AIS having less sway isolated to the anterior-posterior direction. $\underline{15}$ Explanations for the discrepancies include differences in curve characteristics (eg, severity and involved levels) and inconsistent experimental tasks. $\frac{16}{}$ The mechanism of effect of AIS on postural control is also unclear, but studies have noted asymmetrical muscle tone of the rotators of the spine, $\underline{17}, \underline{18}$ probably because of proprioceptive or other sensorimotor defects, $, \underline{13}, \underline{19}, \underline{20}, \underline{21}$ which is centered in the brainstem. $\underline{19}$

Trunk alignment and motion is integral to postural control during functional tasks, and volitional weight-shifting is needed for initiation of gait while also being fundamental to maintaining balance. $\underline{22,23}$ Given that a scoliotic curve distributes extra weight to one limb over the other, it poses a greater challenge to the sensorimotor

Spine Deformity, Vol 4, No. 6 (November 2016): pg. 432-438. DOI. This article is @ Elsevier and permission has been granted for this version to appear in e-Publications@Marquette. Elsevier does not grant permission for this article to be further copied/distributed or hosted elsewhere without the express permission from Elsevier. 
system during weight-shifting to maintain an unopposed stance. $\underline{23}$ Further studies have recognized idiopathic scoliosis to be associated with problems in motor control, $\underline{24}$ so standing balance tasks may not be able to elicit reliable differences in postural control. Studying the volitional weight-shifting ability in those with AIS versus typically developing controls as well as in those with AIS before and after posterior spinal fusion and instrumentation (PSFI) with long-term follow-up should reveal response characteristics to a change in the location of the center of gravity (COG).

The current standard of care for treatment of AIS is PSFI. $\underline{25}, \underline{26}, \underline{27}$ Research has shown that PSFI has high patient satisfaction and qualitative improvements with decreased fatigue and increased daily function. $\underline{25}, \underline{26}, \underline{28}, \underline{29}, \underline{30}$ Studies evaluating the effect of surgery on postural control had short follow-up periods of less than a year and did not stratify by instrumentation levels. O'Beirne et al. showed poorer performance on static postural control tasks at 6 months postoperation, whereas Schimmel et al. showed static and dynamic postural control returning to baseline by 1 year. $\underline{16}, \underline{31}$

Although it is reported that PSFI reduces range of motion, ending instrumentation above L3 or L4 has been inconclusive, with one study showing no difference $\underline{32}$ and one study trending toward significance with respect to decreased range of motion for the L3 and L4 groups. $\frac{26}{2}$ Finally, a third study demonstrated mildly reduced forward flexion with distally extending lowest instrumented vertebra

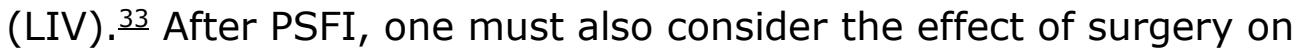
motion at joints distal to the spine. For example, slight increases in pelvic and hip frontal motion have been identified post-operatively in individuals with AIS. $\frac{34}{~ T h e ~ o v e r a l l ~ n e t ~ e f f e c t ~ o f ~ a l t e r a t i o n s ~ i n ~ m o t i o n ~ o f ~}$ the spine and distal joints on functional movement, specifically volitional weight-shifting, has not been investigated. Studying the effect of PSFI on volitional weight-shifting may better inform surgeons when choosing the level of instrumentation given the importance of weight-shifting on walking and functional ability. $\underline{22}$ These results may assist in answering unresolved questions about the impact of fusion to different levels on functional movement.

Spine Deformity, Vol 4, No. 6 (November 2016): pg. 432-438. DOI. This article is @ Elsevier and permission has been granted for this version to appear in e-Publications@Marquette. Elsevier does not grant permission for this article to be further copied/distributed or hosted elsewhere without the express permission from Elsevier. 
Overall, it is uncertain how AIS and subsequent surgical fusion to different levels affects volitional weight-shifting. The aims of the current study are to compare (1) weightbearing symmetry of individuals with AIS to that of a Control Group; and (2) excursions of volitional weight-shifting in individuals with AIS fused to different LIV levels at preoperative and 1 - and 2-year postoperative visits. We hypothesize that (1) there is greater weightbearing asymmetry in the AIS Group when compared to a Control Group; (2) PSFI improves volitional weight-shifting ability; and (3) individuals with PSFI extending to proximal LIV (L2 and above) have greater improvement in volitional weight-shifting postoperatively than individuals with PSFI to more distal LIV (L3 and below).

\section{Material and Methods}

\section{Participants}

This was a prospective study of 41 individuals with AIS ( 8 male, 33 female, age $15.1 \pm 2.1$ years) undergoing PSFI. An additional sample of age range-matched participants (12 male, 12 female, age $16.2 \pm 2.4$ years) were recruited from the general community for the Control Group. All participants and a legal guardian gave informed consent to participate in this institutional review board-approved study (RUSH University Medical Center IRB).

The AIS Group consisted of a sample of convenience between October 2007 and August 2012 at a single specialized pediatric orthopedic institution. A consecutive series of 120 patients had a PSFI, of which 41 patients agreed to participate in the AIS Group. Thirtynine patients made the 1 -year follow-up visit (mean 1.15 years; range, $0.8-1.5$ years) and 31 made the 2 -year visit (mean 2.2 years; range, $1.8-3.4$ years). The inclusion criteria included those diagnosed with AIS and a Cobb angle of $>50^{\circ}$ (group mean Cobb angle $55^{\circ} \pm$ $13^{\circ}$ ). The average age at the time of the PSFI was 15.3 years (range 11.9-18.9 years). Participants were excluded if they required fusion outside T12 through L4. None of the participants had an L5 vertebra above the bicrestilean line or L5 sacralization. Because of safety concerns with the posturography platform, participants were excluded if they could not walk/stand independently as assistive devices could

Spine Deformity, Vol 4, No. 6 (November 2016): pg. 432-438. DOI. This article is @ Elsevier and permission has been granted for this version to appear in e-Publications@Marquette. Elsevier does not grant permission for this article to be further copied/distributed or hosted elsewhere without the express permission from Elsevier. 
disrupt the posturography measurements. We also excluded participants who were pregnant because of the potential effect on the center of gravity. PSFI surgery was performed on all patients in the AIS Group.

The AIS Group was split into two subgroups, L2- Group (fusions to L2 and above) and L3+ Group (fusions to L3 and below), to evaluate the effect of LIV on postural control. There were 15 participants in the L2-Group, of whom 12 made the 1-year follow-up and 10 made the 2 -year visit. There were 26 participants in the L3+ Group, of whom 25 made the first and 22 made the second-year visit. Table 1 lists the demographic data for all participants in the AIS Group.

Table 1. Demographic patient data including gender, age at surgery, weight, height, fusion levels, and lowest instrumented vertebra.

\begin{tabular}{|c|c|c|c|c|c|c|c|}
\hline ID & Gender & Age & Weight, kg & Height, cm & Fusion levels & Group & Lenke class \\
\hline 1 & $\mathrm{~F}$ & 14 & 37.7 & 156.9 & $\mathrm{~T} 2-\mathrm{L} 2$ & L2- & $4(C)$ \\
\hline 2 & $\mathrm{~F}$ & 17 & 55.5 & 154 & T3-L2 & L2- & $1(\mathrm{C})$ \\
\hline 3 & $\mathrm{~F}$ & 18 & 54 & 162.6 & $\mathrm{~T} 2-\mathrm{T} 12$ & L2- & $4(C)$ \\
\hline 4 & $\mathrm{~F}$ & 13 & 55 & 165 & T3-L1 & L2- & $3(C)$ \\
\hline 5 & $\mathrm{~F}$ & 15 & 54.5 & 162.5 & T3-L1 & L2- & $3(B)$ \\
\hline 6 & $\mathrm{~F}$ & 17 & 57.2 & 165.1 & $\mathrm{~T} 2-\mathrm{L} 1$ & L2- & $3(C)$ \\
\hline 7 & $\mathrm{~F}$ & 14 & 62.6 & 168.9 & T3-T12 & L2- & $1(C)$ \\
\hline 8 & $\mathrm{~F}$ & 12 & 63.6 & 158.7 & T3-T12 & L2- & $3(C)$ \\
\hline 9 & $M$ & 16 & 84.5 & 175 & T2-L2 & L2- & $5(C)$ \\
\hline 10 & $M$ & 17 & 80.9 & 175.5 & T3-L2 & L2- & \\
\hline 11 & $\mathrm{~F}$ & 11 & 28.1 & 134.6 & T2-L2 & L2- & $1(C)$ \\
\hline 12 & $\mathrm{~F}$ & 15 & 52.3 & 157 & T4-L1 & L2- & $1(\mathrm{C})$ \\
\hline 13 & $\mathrm{~F}$ & 15 & 45.4 & 160 & $\mathrm{~T} 4-\mathrm{T} 12$ & L2- & $2(B)$ \\
\hline 14 & $\mathrm{~F}$ & 19 & 61.6 & 165.6 & T3-T12 & L2- & $3(C)$ \\
\hline 15 & $\mathrm{~F}$ & 18 & 49.5 & 162 & T4-L2 & L2- & $3(C)$ \\
\hline 16 & $\mathrm{~F}$ & 13 & 45 & 154 & T3-L3 & L3+ & $5(C)$ \\
\hline 17 & $\mathrm{~F}$ & 15 & 53.2 & & T4-L3 & L3+ & $6(C)$ \\
\hline 18 & $\mathrm{~F}$ & 16 & 71.1 & 103.2 & T11-L3 & L3+ & $6(B)$ \\
\hline 19 & $\mathrm{~F}$ & 13 & 34.8 & 143 & T2-L3 & L3+ & $6(C)$ \\
\hline 20 & $\mathrm{~F}$ & 14 & 40.8 & 161.3 & T2-L3 & L3+ & $3(B)$ \\
\hline 21 & $\mathrm{~F}$ & 15 & 44.5 & 155 & T2-L3 & L3+ & $2(C)$ \\
\hline 22 & $\mathrm{~F}$ & 14 & 50 & 164 & T3-L4 & L3+ & $3(C)$ \\
\hline 23 & $\mathrm{~F}$ & 13 & 44.5 & 142 & T3-L4 & $\mathrm{L} 3+$ & $6(C)$ \\
\hline 24 & $\mathrm{~F}$ & 20 & 46.4 & 157.5 & T2-L4 & L3+ & $1(C)$ \\
\hline 25 & $\mathrm{~F}$ & 17 & 52.7 & 164.4 & T4-L4 & L3+ & $6(C)$ \\
\hline
\end{tabular}

Spine Deformity, Vol 4, No. 6 (November 2016): pg. 432-438. DOI. This article is (C) Elsevier and permission has been granted for this version to appear in e-Publications@Marquette. Elsevier does not grant permission for this article to be further copied/distributed or hosted elsewhere without the express permission from Elsevier. 
NOT THE PUBLISHED VERSION; this is the author's final, peer-reviewed manuscript. The published version may be accessed by following the link in the citation at the bottom of the page.

\begin{tabular}{|c|c|c|c|c|c|c|c|}
\hline ID & Gender & Age & Weight, kg & Height, cm & Fusion levels & Group & Lenke class \\
\hline 26 & $\mathrm{~F}$ & 18 & 50.3 & 157.5 & T3-L3 & $\mathrm{L} 3+$ & $1(C)$ \\
\hline 27 & $\mathrm{~F}$ & 12 & 47.7 & 155 & T3-L3 & $\mathrm{L} 3+$ & $1(C)$ \\
\hline 28 & $M$ & 15 & 50.9 & 152.5 & T2-L3 & L3+ & $1(C)$ \\
\hline 29 & $\mathrm{~F}$ & 16 & 53.6 & 160 & T3-L4 & L3+ & $3(C)$ \\
\hline 30 & $\mathrm{~F}$ & 15 & 52.3 & 170.2 & T10-L3 & L3+ & $5(C)$ \\
\hline 31 & $M$ & 16 & 53.2 & 166.4 & T3-L3 & L3+ & $3(C)$ \\
\hline 32 & $\mathrm{~F}$ & 17 & 54.1 & 176 & T4-L4 & L3+ & $3(C)$ \\
\hline 33 & $\mathrm{~F}$ & 13 & 61.7 & 167 & T3-L4 & L3+ & $2(C)$ \\
\hline 34 & $\mathrm{~F}$ & 13 & 60.5 & 170 & T3-L4 & L3+ & $6(C)$ \\
\hline 35 & $\mathrm{~F}$ & 13 & 56.6 & 159 & T2-L4 & L3+ & $3(C)$ \\
\hline 36 & M & 16 & 64.1 & 167 & T3-L3 & L3+ & $3(C)$ \\
\hline 37 & $\mathrm{~F}$ & 16 & 65 & 160 & T4-L4 & L3+ & $6(C)$ \\
\hline 38 & $\mathrm{~F}$ & 12 & 65.9 & 161.9 & T4-L4 & L3+ & $3(C)$ \\
\hline 39 & $\mathrm{~F}$ & 17 & 71.3 & 170 & T2-L4 & L3+ & $2(C)$ \\
\hline 40 & $\mathrm{~F}$ & 15 & 89.7 & 165 & T3-L3 & L3+ & $2(C)$ \\
\hline 41 & $M$ & 15 & 47.3 & 167 & T3-L4 & L3+ & $3(C)$ \\
\hline
\end{tabular}

This chart is reprinted from Spine Deformity. $\frac{26}{3}$

\section{Experimental procedure}

Participants in both the Control and AIS Groups underwent weightbearing symmetry and volitional weight-shifting tasks on a computerized posturography platform (Neurocom SMART EquiTest, Natus Medical Inc.) using the Motor Control Test and Limits of Stability protocols (see Fig. 1). Weight symmetry was measured as a percentage deviation from equal weightbearing through the bilateral lower extremities ( $0=$ symmetrical weightbearing and $100=$ complete weightbearing through either the right or left lower extremity).

Spine Deformity, Vol 4, No. 6 (November 2016): pg. 432-438. DOI. This article is C Elsevier and permission has been granted for this version to appear in e-Publications@Marquette. Elsevier does not grant permission for this article to be further copied/distributed or hosted elsewhere without the express permission from Elsevier. 


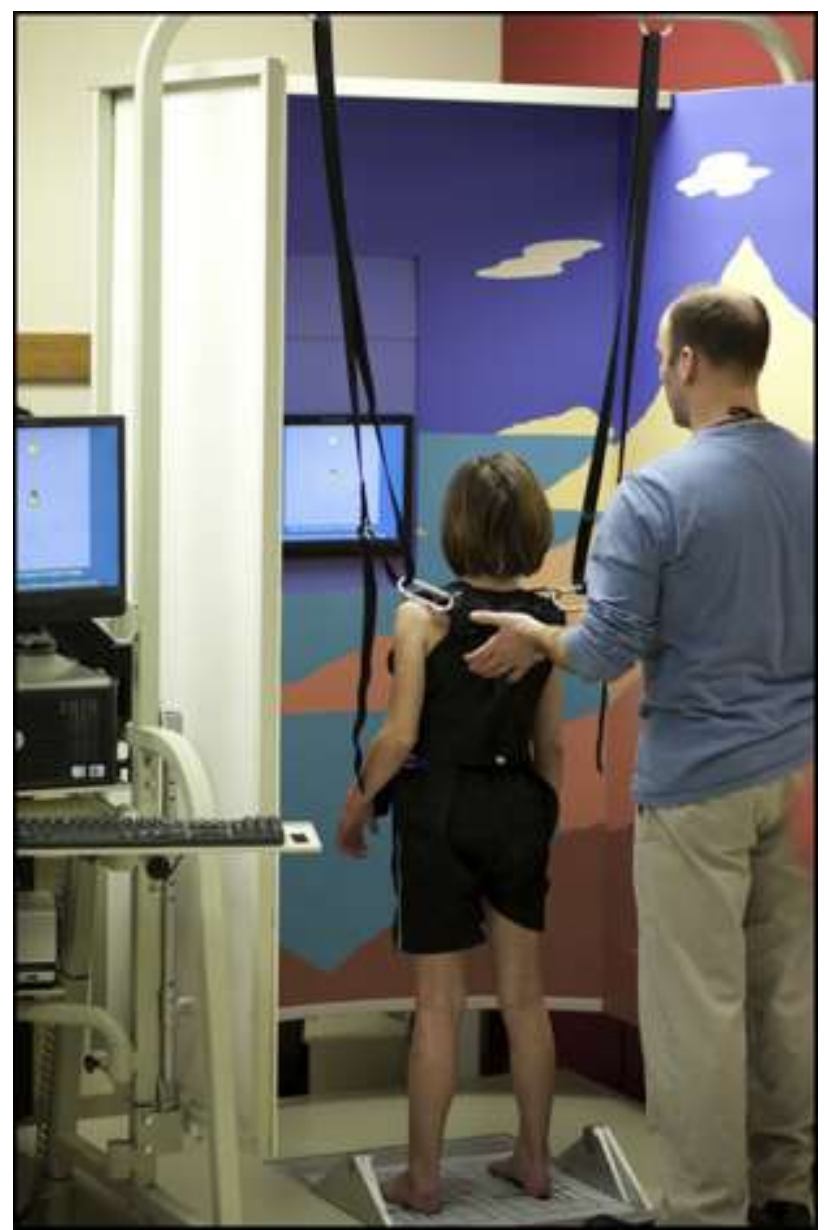

Fig. 1. Neurocom SMART EquiTest computerized posturography platform.

For volitional weight-shifting, a dynamic balance task was performed in which subjects stood on a platform facing a computer screen that displayed their COG as a moving cursor (Fig. 1). We used the NeuroCom Limits of Stability protocol (LOS), an objectively measured test of volitional weight-shifting that is valid and reliable. $\underline{35}$ LOS testing has been previously shown to have high test-retest reliability, across subsequent retrials even when the retest occurred within 1 week. $\underline{35}, \underline{36}, \underline{37}$ All participants, including those of the Control Group underwent this task with a single trial at their initial visit. Members of the AIS Group repeated the test at 1 and 2 years postoperatively. The screen presented 8 targets in the cardinal directions (front, left-front, left, left-back, back, right-back, right, right-front) at the patient's theoretical limit of stability in each direction (Fig. 2). $\frac{35}{}$ The participants were then instructed to shift their COG to move the cursor to the targets sequentially while keeping their 
feet plantigrade on the platform. The endpoint excursion (EPE), maximum endpoint excursion (MXE), and MXE-EPE were used as measures of the volitional weight-shifting ability (see Fig. 3). The EPE was defined as the percentage distance reached toward the target in the initial weight-shift in the intended direction, prior to any correction. The MXE was defined as the greatest percentage of distance the participant reaches toward the target during the trial. The MXE reflects the maximal weight-shifting distance beyond the EPE in the intended direction. The MXE-EPE was defined as the subtractive difference between MXE and EPE and was intended to be a measure of correction. Healthy adults should reach $100 \%$ on both EPE and MXE. .55

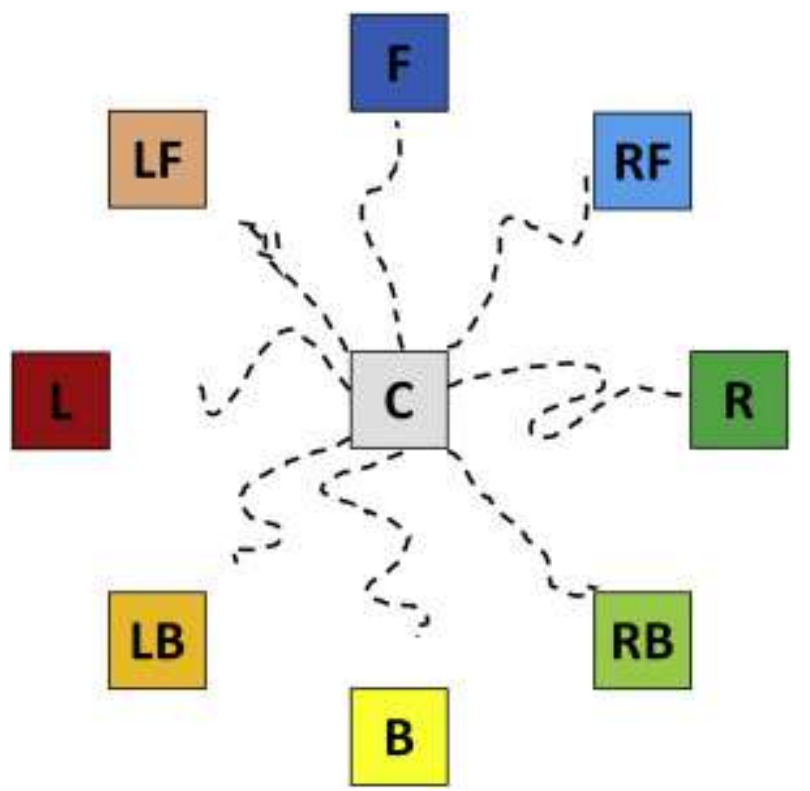

Fig. 2. Neurocom dynamic balance task-limits of stability.

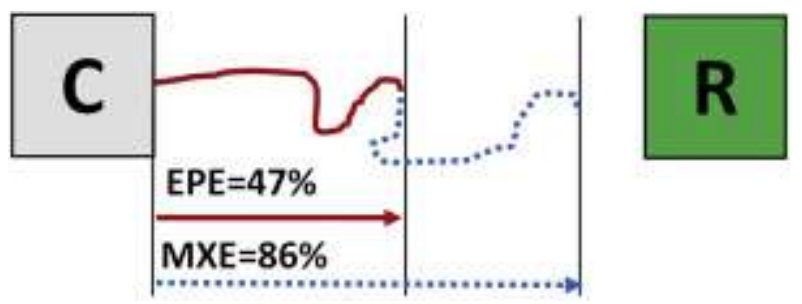

Fig. 3. An example of endpoint excursion (EPE) and maximum endpoint excursion (MXE) measures of weight-shifting to the right (R). A participant begins a trial by maintaining the cursor in the center $(C)$ target. The participant then moves the cursor by shifting his or her weight toward a target in one of the cardinal directions. 
We defined cardinal left as the average MXE or EPE values for the left-facing targets (front-left, left, and back-left). We focused on cardinal left as a majority of individuals with AIS have a primary curve that is convex to the right, and we surmised the weight-shifting to be most compromised to the left as supported by noted increased sway to the right. 3

\section{Statistical analysis}

A Mann-Whitney $U$ test was performed to compare median weightbearing symmetry scores between the AIS and Control Groups. Regression equations were used to evaluate the effect of PSFI ( 1 and 2 years postoperatively) and effect of LIV (L2- Vs. L3+ subgroups) on measures of volitional weight-shifting, using the MXE, EPE, and MXEEPE measures for the cardinal left direction. Given multiple comparisons done in this study, we set our significant threshold (alpha) at $p=.01$. Statistical calculations were made using SAS (IBM, Armonk, NY).

\section{Results}

\section{Weightbearing symmetry}

Individuals with AIS had greater preoperative weightbearing asymmetry when compared with the Control Group (AIS Group, 10\%; Control Group, 5\%, $p=.01$ ), as shown in Figure 4. 
NOT THE PUBLISHED VERSION; this is the author's final, peer-reviewed manuscript. The published version may be accessed by following the link in the citation at the bottom of the page.

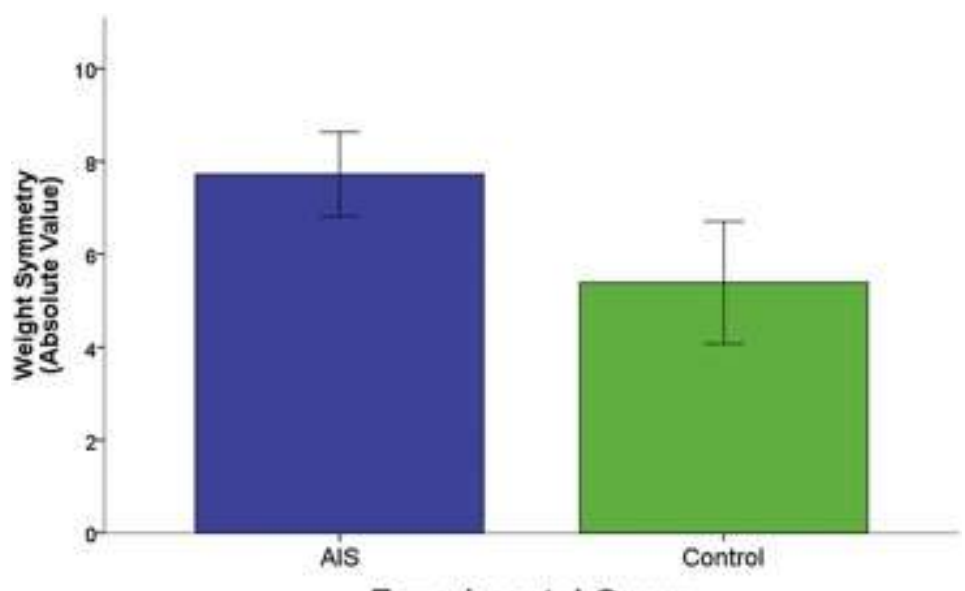

Experimental Group

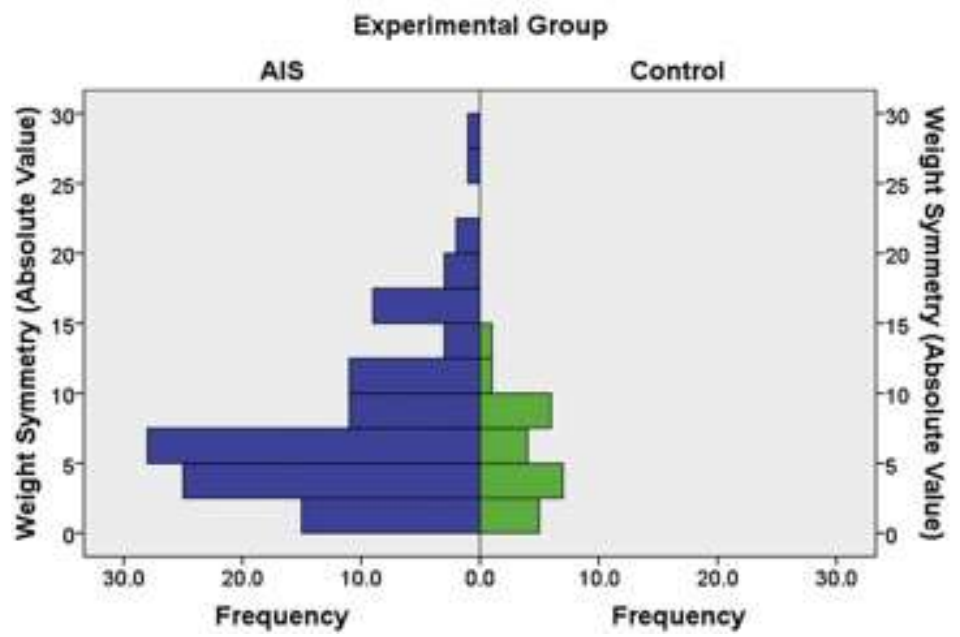

Fig. 4. Comparison between preoperative weight symmetry in the AIS versus Control Groups $(0=$ symmetrical weightbearing and $100=$ complete weightbearing through either the right or left lower extremity).

\section{Dynamic weight-shifting task}

At baseline, the Control Group had the following values for cardinal left: $\mathrm{EPE}=76 \%$ and $\mathrm{MXE}=90 \%$. The AIS Group performed better on the tasks at baseline, with EPE $=84 \%$ and $\mathrm{MXE}=95 \%$ (see Fig. 5 and Fig. 6). There was a significant difference between the EPE $(p<.01)$ but not MXE $(p=.02)$ when comparing the AIS Group to the Control Group at baseline. Fig. 5, Fig. 6 and Fig. 7 show the cardinal left EPE, MXE, and the difference between the two (MXE-EPE) from baseline to the first- and second-year visits. Compared with the preoperative evaluation, there was a significant effect of surgery by the second postoperative year during volitional weight-shifting on EPE

Spine Deformity, Vol 4, No. 6 (November 2016): pg. 432-438. DOI. This article is (C) Elsevier and permission has been granted for this version to appear in e-Publications@Marquette. Elsevier does not grant permission for this article to be further copied/distributed or hosted elsewhere without the express permission from Elsevier. 
$(p<.01)$ and MXE-EPE $(p<.01)$ but not MXE $(p<.01)$ in both AIS subgroups. There was no main effect of LIV on volitional weightshifting, as participants demonstrated similar EPE, MXE, and MXE-EPE values by the second postoperative year.

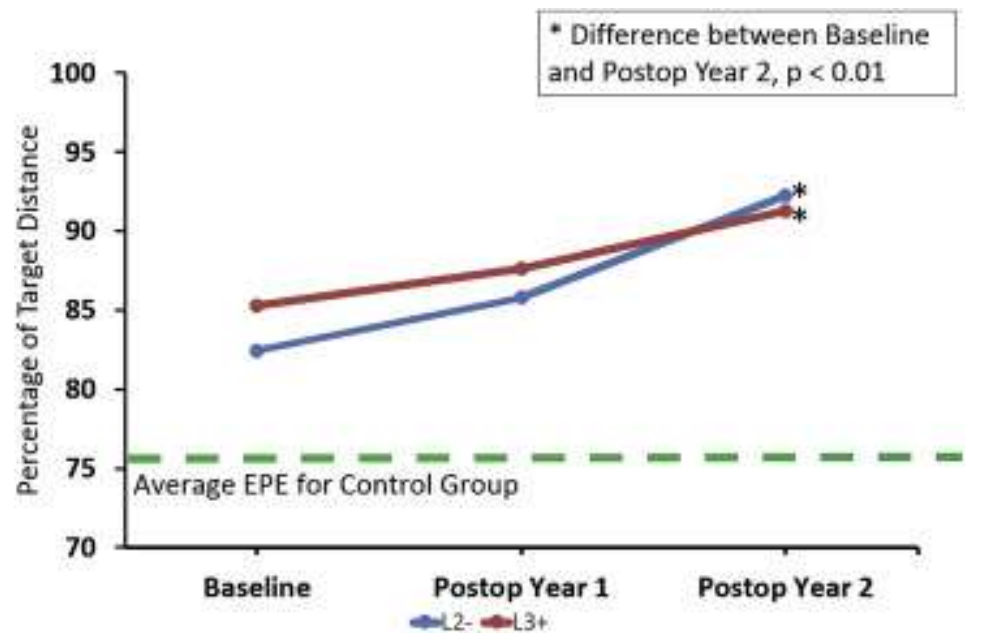

Fig. 5. Cardinal left EPE. EPE, endpoint excursion.

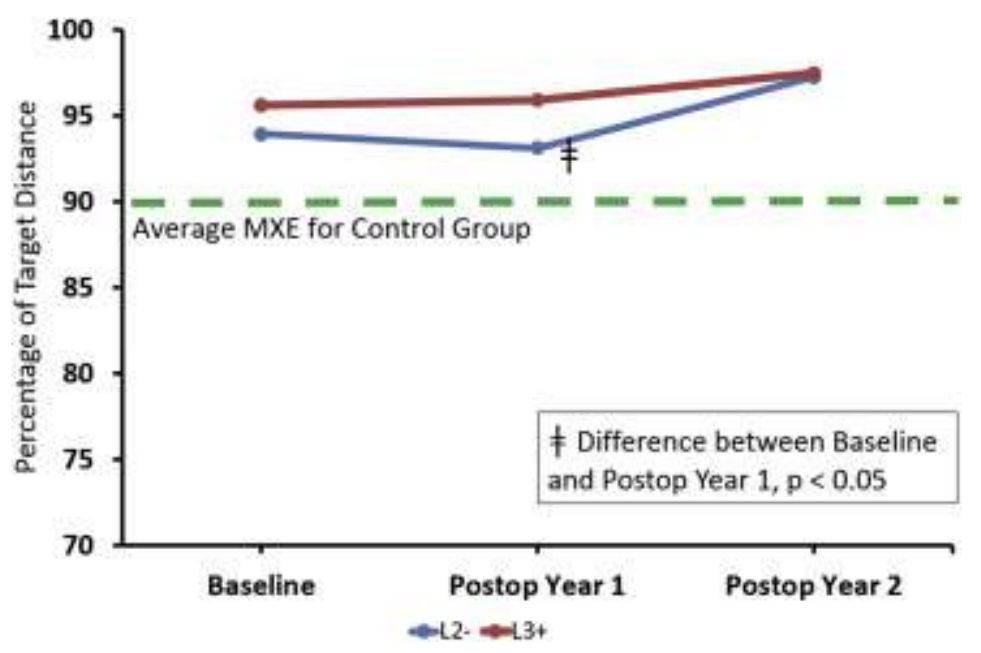

Fig. 6. Cardinal left MXE. MXE, maximum endpoint excursion. 
NOT THE PUBLISHED VERSION; this is the author's final, peer-reviewed manuscript. The published version may be accessed by following the link in the citation at the bottom of the page.

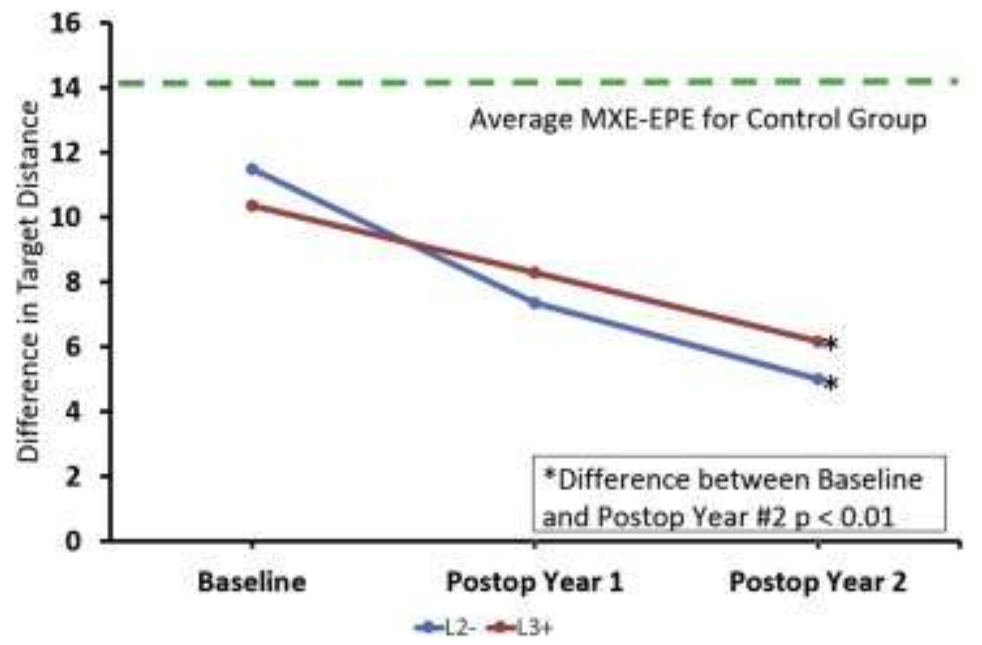

Fig. 7. Cardinal left MXE-EPE. EPE, endpoint excursion; MXE, maximum endpoint excursion.

\section{Radiographic assessment}

Table 2 describes the preoperative and postoperative radiographic data for the participants in the AIS group. The AIS group had a mean preoperative Cobb angle of $55^{\circ} \pm 13^{\circ}$, which decreased to $23 \pm 7$ at the Year 1 and $24 \pm 8$ at the Year 2 postoperative visit.

Table 2. Summary of radiographic data by group.

Preoperation Postoperative Year 1 Postoperative Year $2 \%$ correction Cobb angle (major curve)

$\begin{array}{llll}\text { All } 55.1 \pm 13.0 & 23.4 \pm 6.8 & 23.7 \pm 7.7 & 54.6 \pm 19.5 \\ \text { L2- } 51.4 \pm 9.3 & 22.9 \pm 6.7 & 21.8 \pm 6.4 & 58.1 \pm 10.8 \\ \text { L3+ 57.0 } \pm 14.3 & 23.6 \pm 7.0 & 24.8 \pm 8.3 & 52.7 \pm 22.8\end{array}$

Cobb angle (minor curve)

$\begin{array}{llll}\text { All } 40.3 \pm 9.8 & 20.9 \pm 6.8 & 21.8 \pm 7.3 & 42.1 \pm 26.3 \\ \text { L2- } 38.0 \pm 6.5 & 20.9 \pm 8.5 & 21.4 \pm 8.5 & 41.4 \pm 26.1 \\ \text { L3+ } 41.4 \pm 11.1 & 20.8 \pm 6.1 & 22.0 \pm 6.9 & 42.5 \pm 27.1\end{array}$

Coronal plane imbalance (trunk shift)
All $1.13 \pm 1.52$
$1.08 \pm 1.36$
$0.85 \pm 0.82$
L2 $-0.88 \pm 1.62$
$1.03 \pm 1.68$
$0.66 \pm 0.69$
$\mathrm{L} 3+1.28 \pm 1.48$
$1.12 \pm 1.16$
$0.96 \pm 0.88$

Sagittal plane imbalance
All $\quad-1.30 \pm 2.58-3.23 \pm 2.59$
$-2.99 \pm 2.99$
L2 $--1.66 \pm 2.84-3.29 \pm 2.62$
$-3.31 \pm 2.87$
$\mathrm{L} 3+-1.11 \pm 2.41$
$-3.19 \pm 2.62$
$-2.80 \pm 3.09$

Pelvic incidence angle
All $\quad 53.5 \pm 13.0$
$53.3 \pm 13.2$
$53.8 \pm 13.0$

Spine Deformity, Vol 4, No. 6 (November 2016): pg. 432-438. DOI. This article is (C) Elsevier and permission has been granted for this version to appear in e-Publications@Marquette. Elsevier does not grant permission for this article to be further copied/distributed or hosted elsewhere without the express permission from Elsevier. 
NOT THE PUBLISHED VERSION; this is the author's final, peer-reviewed manuscript. The published version may be accessed by following the link in the citation at the bottom of the page.

\begin{tabular}{|c|c|c|}
\hline Preoperation & Postoperative Year 1 & Postoperative Year $2 \%$ correction \\
\hline $2-55$. & $49.9 \pm 12.6$ & $50.0 \pm 13.7$ \\
\hline $3+52.6 \pm 14.0$ & $55.0 \pm 13.3$ & $56.0 \pm 12.4$ \\
\hline
\end{tabular}

\section{Discussion}

Scoliosis consistently affected weightbearing distribution through the lower extremities. Participants in the AIS Group presented with greater weightbearing asymmetry preoperatively than the Control Group. As the asymmetry occurs during unopposed standing, this would support a biomechanical cause: because of the effects of the musculoskeletal deformity, individuals with AIS have a baseline center of mass shifted away from midline. This was consistent with many prior studies showing increased sway in participants with AIS. There are still a number of studies that do not show this difference. As previously mentioned, studies have varied considerably with respect to experimental tasks and the degree of severity of scoliosis, though they tend to implicate sensorimotor mechanisms. $\underline{1}, \underline{13}, \underline{19}, \underline{20}, \underline{21}$

Neither the Control nor AIS Group consistently reached their limit of stability in the volitional weight-shifting tasks (their expected EPE and MXE would be $100 \%$ for typically developed adults). As adolescents have to contend with physical growth, they may be expected to perform worse on the tasks than a typical adult. Indeed, children and adolescents perform better on dynamic posturography tasks as they grow and develop. $\underline{38}$ However, even at baseline, the AIS group performed better than the Control Group on EPE but not MXE, which suggests they learn to improve the initial accuracy of their weight-shifts despite an aberrant center of gravity. Compared with baseline, the AIS subgroups had better performance on EPE by the second preoperative year. This suggests that PSFI improves the accuracy of their weight-shifting in concert with moving their COG toward the midline. Their overall limit of weight-shifting, measured by MXE, remained indistinguishable from controls at 2 years postoperation and did not appear to be affected by scoliosis or corrective surgery, in contrast with EPE. Although the present study results are consistent with the two prior studies of PSFI on postural control at 6 months and 1 year, this study has the benefit of showing continued improvement in volitional weight-shifting by the second postoperative year. $\underline{16}, \underline{31}$

Spine Deformity, Vol 4, No. 6 (November 2016): pg. 432-438. DOI. This article is @ Elsevier and permission has been granted for this version to appear in e-Publications@Marquette. Elsevier does not grant permission for this article to be further copied/distributed or hosted elsewhere without the express permission from Elsevier. 
With respect to the effect of LIV on weight-shifting, the L3+ Group unexpectedly demonstrated greater volitional weight-shifting accuracy (EPE) at 1 year postoperation compared with $\mathrm{L} 2-$ that approached significance $(p=.02)$. There were no differences by the second year postoperation. The L3+ Group also showed decrease in MXE-EPE, suggesting that they need less readjustment of their initial weight-shift than preoperatively. Although prior studies were inconsistent on the change in spinal motion at unfused levels at 2 years, $\underline{26}, \underline{32}, \underline{39}$ this did not appear to affect individuals' volitional weightshifting ability in the present study. Within the same cohort, the L3+ group had increased range of motion in a prior study that approached significance $(p=.04)$ between the first and second year

postoperation. $\underline{26}$ Overall, volitional weight-shifting ability appeared to be inversely or at least independently related to range of motion. Counterintuitively, a restriction in range of motion may provide additional stability and ultimately more accurate volitional weightshifting along with a restored midline COG. Nonetheless, the further restriction in instrumenting below $L 3$ does not appear to significantly affect this accuracy to warrant change in current surgical practice.

The present study benefited from a relatively large sample size, homogenous surgical technique (PSFI only), and long-term follow-up. However, the study could have benefited from long-term follow-up in the Control Group to eliminate natural adolescent growth as a potential confounding factor. Given that patients with both left convex and right convex spinal curves had center of sway in lateral plane directed to the right, 3 we were primarily interested in the volitional weight-shifts toward the left, away from the center of gravity. Overall, we found that participants in the AIS and Control Groups showed differences in weightbearing symmetry. Participants in the AIS group improved on volitional weight-shifting after PSFI, and there was no difference between the L2+ and L3- subgroups on postoperative volitional weight control.

\section{Conclusions}

Individuals with AIS have a shifted COG from midline compared with typically developing controls. Although previous reports have identified that fusion to more distal segments affected trunk motion

Spine Deformity, Vol 4, No. 6 (November 2016): pg. 432-438. DOI. This article is @ Elsevier and permission has been granted for this version to appear in e-Publications@Marquette. Elsevier does not grant permission for this article to be further copied/distributed or hosted elsewhere without the express permission from Elsevier. 
after PSFI, in this study it did not affect an individual's post-operative improvement in volitional weight-shifting. There was no indication that adjustment of LIV level would minimize the risk of postoperative postural control impairment. Other than LIV, factors such as preoperative weightbearing symmetry and curve characteristics may also impact volitional weight-shifting and warrant further inquiry. Because improvements of weightshifting after PSFI continued 2 years postoperatively, future studies may also investigate postural control further in the long term and development of compensatory mechanisms.

\section{Key points}

- Individuals with adolescent idiopathic scoliosis (AIS) have greater weightbearing asymmetry but improved volitional weight-shifting over typically developing controls.

- Posterior spinal fusion and instrumentation (PSFI) improves volitional weight-shifting beyond the preoperative baseline.

- No difference in postural control by postoperative year 2 with respect to lowest instrumented vertebra group (L2 and above vs. L3 and below).

\section{References}

1M. Beaulieu, C. Toulotte, L. Gatto, et al. Postural imbalance in non-treated adolescent idiopathic scoliosis at different periods of progression. Eur Spine J, 18 (2009), pp. 38-44

2N.N. Byl, J.M. Gray. Complex balance reactions in different sensory conditions: adolescents with and without idiopathic scoliosis. J Orthop Res, 11 (1993), pp. 215-227

3 T. Sahlstrand, R. Ortengren, A. Nachemson. Postural equilibrium in adolescent idiopathic scoliosis. Acta Orthop Scand, 49 (1978), pp. 354-365

4T. Haumont, G.C. Gauchard, P. Lascombes, P.P. Perrin. Postural instability in early-stage idiopathic scoliosis in adolescent girls. Spine (Phila Pa 1976), 36 (2011), pp. E847-E854

5 M.-L. Nault, P. Allard, S. Hinse, et al. Relations between standing stability and body posture parameters in adolescent idiopathic scoliosis. Spine (Phila Pa 1976), 27 (2002), pp. 1911-1917

6 P. Chen, J. Wang, Y. Tsuang, T. Liao. The postural stability control and gait pattern of idiopathic scoliosis adolescents. Clin Biomech (Bristol, Avon), 13 (1 suppl 1) (1998), pp. S52-S58

Spine Deformity, Vol 4, No. 6 (November 2016): pg. 432-438. DOI. This article is (c) Elsevier and permission has been granted for this version to appear in e-Publications@Marquette. Elsevier does not grant permission for this article to be further copied/distributed or hosted elsewhere without the express permission from Elsevier. 
NOT THE PUBLISHED VERSION; this is the author's final, peer-reviewed manuscript. The published version may be accessed by following the link in the citation at the bottom of the page.

7M. Simoneau, N. Richer, P. Mercier, et al. Sensory deprivation and balance control in idiopathic scoliosis adolescent. Exp Brain Res, 170 (2006), pp. 576-582

8M. Simoneau, P. Mercier, J. Blouin, et al. Altered sensory-weighting mechanisms is observed in adolescents with idiopathic scoliosis. BMC Neurosci, 7 (2006), p. 68

9K.F. Zabjek, M.A. Leroux, C. Coillard, et al. Evaluation of segmental postural characteristics during quiet standing in control and idiopathic scoliosis patients. Clin Biomech, 20 (2005), pp. 483-490

10M. Gregoric, F. Pecak, J.V. Trontelj, M.R. Dimitrijević. Postural control in scoliosis. A statokinesimetric study in patients with scoliosis due to neuromuscular disorders and in patients with idiopathic scoliosis. Acta Orthop Scand, 52 (1981), pp. 59-63

${ }^{11}$ F.-C. Kuo, C.-Z. Hong, C.-L. Lai, S.-H. Tan. Postural control strategies related to anticipatory perturbation and quick perturbation in adolescent idiopathic scoliosis. Spine (Phila Pa 1976), 36 (2011), pp. 810-816

12 N.N. Byl, S. Holland, A. Jurek, S.S. Hu. Postural imbalance and vibratory sensitivity in patients with idiopathic scoliosis: implications for treatment. J Orthop Sports Phys Ther, 26 (1997), pp. 60-68

${ }^{13}$ C. Assaiante, S. Mallau, J.L. Jouve, et al. Do adolescent idiopathic scoliosis (AIS) neglect proprioceptive information in sensory integration of postural control? PLoS One, 7 (2012), pp. 1-9

${ }^{14}$ R. Herman, R. Maulucci, J. Stuyck. Development and plasticity of visual and vestibular generated eye movements. Exp Brain Res, 47 (1982), pp. $69-78$

$\underline{15}$ N. Adler, E.E. Bleck, L.A. Rinsky, W. Young. Balance reactions and eye-hand coordination in idiopathic scoliosis. J Orthop Res, 4 (1986), pp. 102107

16].J. Schimmel, B.E. Groen, V. Weerdesteyn, M. de Kleuver. Adolescent idiopathic scoliosis and spinal fusion do not substantially impact on postural balance. Scoliosis, 10 (2015), p. 18

17X. Guo, W.W. Chau, C.W.Y. Hui-Chan, et al. Balance control in adolescents with idiopathic scoliosis and disturbed somatosensory function. Spine (Phila Pa 1976), 31 (2006), pp. E437-E440

18]. Trontelj, F. Pecak, M. Dimitrijevic. Segmental neurophysiological mechanisms in scoliosis. J Bone Joint Surg Br, 61-B (1979), pp. 310313

${ }^{19} \mathrm{~K}$. Yamada, H. Yamamoto, Y. Nakagawa, et al. Etiology of idiopathic scoliosis. Clin Orthop Relat Res (1984), pp. 50-57

${ }^{20}$ W. Yoslow, M.H. Becker, J. Bartels, W.A. Thompson. Orthopaedic defects in familial dysautonomia. A review of sixty-five cases. J Bone Joint Surg Am, 53 (1971), pp. 1541-1550

Spine Deformity, Vol 4, No. 6 (November 2016): pg. 432-438. DOI. This article is @ Elsevier and permission has been granted for this version to appear in e-Publications@Marquette. Elsevier does not grant permission for this article to be further copied/distributed or hosted elsewhere without the express permission from Elsevier 
NOT THE PUBLISHED VERSION; this is the author's final, peer-reviewed manuscript. The published version may be accessed by following the link in the citation at the bottom of the page.

21 R.L. Barrack, T.S. Whitecloud, S.W. Burke, et al. Proprioception in idiopathic scoliosis. Spine (Phila Pa 1976), 9 (1984), pp. 681-685

22KK. Hiraoka, R. Hatanaka, Y. Nikaido, et al. Asymmetry of anticipatory postural adjustment during gait initiation. J Hum Kinet, 42 (2014), pp. 7-14

${ }^{23}$ A.V. Bruyneel, P. Chavet, G. Bollini, et al. Dynamical asymmetries in idiopathic scoliosis during forward and lateral initiation step. Eur Spine J, 18 (2009), pp. 188-195

${ }^{24} \mathrm{R}$. Herman, J. Mixon, A. Fisher, et al. Idiopathic scoliosis and the central nervous system: a motor control problem. The Harrington Lecture, 1983. Scoliosis Research Society. Spine (Phila Pa 1976), 10 (1985), pp. $1-14$

$\underline{25}$ R.M. Ali, O. Boachie-Adjei, B.A. Rawlins. Functional and radiographic outcomes after surgery for adult scoliosis using third-generation instrumentation techniques. Spine (Phila Pa 1976), 28 (2003), pp. 1163-1169 discussion 1169-70

26 U.I. Udoekwere, J.J. Krzak, A. Graf, et al. Effect of lowest instrumented vertebra on trunk mobility in patients with adolescent idiopathic scoliosis undergoing a posterior spinal fusion. Spine Deform, 2 (2014), pp. 291-300

27].A. Byrd, P.V. Scoles, R.B. Winter, et al. Adult idiopathic scoliosis treated by anterior and posterior spinal fusion. J Bone Joint Surg Am, 69 (1987), pp. $843-850$

28 M.A. Asher, D.C. Burton. Adolescent idiopathic scoliosis: natural history and long term treatment effects. Scoliosis, 1 (2006), p. 2

29M.S. Wong, A.F. Mak, K.D. Luk, et al. Effectiveness of audio-biofeedback in postural training for adolescent idiopathic scoliosis patients. Prosthet Orthot Int, 25 (2001), pp. 60-70

30 N.C. Islam, K.B. Wood, E.E. Transfeldt, et al. Extension of fusions to the pelvis in idiopathic scoliosis. Spine (Phila Pa 1976), 26 (2001), pp. $166-173$

31]. O'Beirne, C. Goldberg, F.E. Dowling, E.E. Fogarty. Equilibrial dysfunction in scoliosis-cause or effect? J Spinal Disord, 2 (1989), pp. 184-189

32].R. Engsberg, L.G. Lenke, A.K. Reitenbach, et al. Prospective evaluation of trunk range of motion in adolescents with idiopathic scoliosis undergoing spinal fusion surgery. Spine (Phila Pa 1976), 27 (2002), pp. $1346-1354$

33]. Sanchez-Raya, J. Bago, F. Pellise, et al. Does the lower instrumented vertebra have an effect on lumbar mobility, subjective perception of trunk flexibility, and quality of life in patients with idiopathic scoliosis treated by spinal fusion? J Spinal Disord Tech, 25 (2012), pp. 437-442

Spine Deformity, Vol 4, No. 6 (November 2016): pg. 432-438. DOI. This article is (C) Elsevier and permission has been granted for this version to appear in e-Publications@Marquette. Elsevier does not grant permission for this article to be further copied/distributed or hosted elsewhere without the express permission from Elsevier. 
NOT THE PUBLISHED VERSION; this is the author's final, peer-reviewed manuscript. The published version may be accessed by following the link in the citation at the bottom of the page.

${ }^{34} \mathrm{P}$. Mahaudens, C. Detrembleur, M. Mousny, X. Banse. Gait in thoracolumbar/lumbar adolescent idiopathic scoliosis: effect of surgery on gait mechanisms. Eur Spine J, 19 (2010), pp. 1179-1188

35 M.L. Pickerill, R.A. Harter. Validity and reliability of limits-of-stability testing: a comparison of 2 postural stability evaluation devices. J Ath/ Train, 46 (2011), pp. 600-606

36 N. Takeshima, M.M. Islam, M.E. Rogers, et al. Pattern of age-associated decline of static and dynamic balance in community-dwelling older women. Geriatr Gerontol Int, 14 (2014), pp. 556-560

37T. Szturm, V. Sakhalkar, S. Boreskie, et al. Integrated testing of standing balance and cognition: Test-retest reliability and construct validity. Gait Posture, 41 (2015), pp. 146-152

38 S. Barozzi, M. Socci, D. Soi, et al. Reliability of postural control measures in children and young adolescents. Eur Arch Otorhinolaryngol, 271 (2014), pp. 2069-2077

${ }^{39}$ B. Wilk, L.A. Karol, C.E. Johnston, et al. The effect of scoliosis fusion on spinal motion: a comparison of fused and nonfused patients with idiopathic scoliosis. Spine (Phila Pa 1976), 31 (2006), pp. 309-314

Author disclosures: NTK (grants from U.S. Department of Health and Human Services-National Institute on Disability, Independent Living, and Rehabilitation Research, during the conduct of the study); JJK (none); AG (none); SH (none); ST (none); PFS (none); KH (none); PG (none); GFH (none).

The study was supported by a grant from the U.S. Department of Health and Human Services-National Institute on Disability, Independent Living, and Rehabilitation Research (NIDILRR): Advanced Rehabilitation Research Training in Pediatric Mobility for Physicians and Engineers. 90AR5022-01-00 (Formerly H133P140023-14). The contents of this manuscript do not necessarily represent the policy of NIDILRR, ACL, HHS, and one should not assume endorsement by the Federal Government. Support for the study also came from the Hainer Foundation and DePuy Spine.

Corresponding author. Orthopedic and Rehabilitation Engineering Center (OREC), Marquette University and the Medical College of Wisconsin, Olin Engineering Center, Room 323, PO Box 1881, Milwaukee, WI 53201-1881, USA. Tel.: +1-414-288-6796; fax: +1-262-785-1780.

Spine Deformity, Vol 4, No. 6 (November 2016): pg. 432-438. DOI. This article is @ Elsevier and permission has been granted for this version to appear in e-Publications@Marquette. Elsevier does not grant permission for this article to be further copied/distributed or hosted elsewhere without the express permission from Elsevier. 